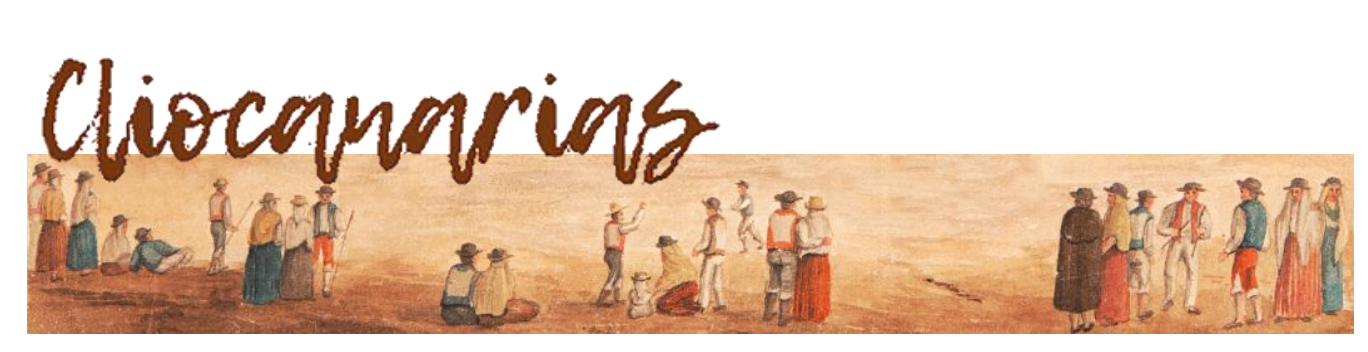

ISSN 2695-4494

https://doi.org/10.53335/cliocanarias.2021.3.21

\title{
MI ENTREVISTA CON ADOLFO SUÁREZ \\ PARA ALUMNOS DE BACHILLERATO
}

MY INTERVIEW WITH ADOLFO SUÁREZ FOR HIGH SCHOOL STUDENTS

Facundo DARANAS VENTURA*

RESUMEN: En 1983, con motivo de la estancia del expresidente Adolfo Suárez en Santa Cruz de La Palma, le solicité una entrevista para explicar mejor a los alumnos de Bachillerato la Transición española, que aún no figuraba en la programación oficial. Se ofrece aquí, en su contexto, ese encuentro con Suárez a través de la transcripción de sus palabras y en formato de audición.

PALABRAS ClAVE: Transición, Adolfo Suárez, reforma política, elecciones.

ABSTRACT: In 1983, on the occasion of the stay of former President Adolfo Suárez in Santa Cruz de La Palma, I requested an interview to better explain to the high school students the Spanish Transition, which was not yet on the official schedule. This encounter with Suárez is offered here, in its context, through the transcription of his words and in audition format.

KEYWORDS: Transition, Adolfo Suárez, political reform, elections.

En julio de 1982 el expresidente del Gobierno Adolfo Suárez, junto a antiguos compañeros de Unión de Centro Democrático, UCD, fundaron el Centro Democrático y Social, CDS, del que fue elegido presidente. Presentada a las elecciones generales, celebradas en octubre de ese mismo año, la nueva formación obtuvo dos diputados, el propio Adolfo Suárez y Agustín Rodríguez Sahagún, frente a la mayoría absoluta alcanzada por el PSOE, liderado por Felipe González, con doscientos dos congresistas. Unos años más tarde, en 1986, el CDS remontó su anterior resultado obteniendo diecinueve diputados. Y un año después, en las elecciones municipales, autonómicas y europeas de 1987, el partido logró formar coalición para hacerse con la Presidencia del Gobierno de Canarias.

Años antes, el 22 de marzo de 1983, Adolfo Suárez vino a Santa Cruz de La Palma, donde ofreció un mitin en el Teatro Circo de Marte. Por aquel entonces yo era profesor agregado de Geografia e Historia en el Instituto de Bachillerato Alonso Pérez Díaz de la capital insular, donde tenía mi plaza. Impartía, entre otras, la materia de Historia de España para alumnos de tercer curso de BUP (Bachillerato Unificado Polivalente), un grupo de alumnos verdaderamente aplicado, con curiosidad y ganas de aprender.

\footnotetext{
* Profesor de enseñanza secundaria. C. e.: fdaranas@hotmail.com
} 
Evidentemente, el tema de la Transición aún no figuraba en los programas oficiales del Ministerio de Educación. En los libros de texto el siglo XX terminaba con la Proclamación de Juan Carlos como rey de España, con una extensión de catorce líneas divididas en cuatro párrafos.

Sin embargo, como profesor intuía algo que ya era evidente; es decir, que la Transición sería un tema que, además de crucial trascendencia, llegaría a formar parte en un futuro del temario oficial de Bachillerato en la materia Historia de España y que Adolfo Suárez entraria en la historia, como así sucedió.

Pensé, entonces, en lo interesante que sería aprovechar esta visita de Adolfo Suárez a Santa Cruz de La Palma para pedirle unas palabras sobre la Transición dirigidas a unos futuros alumnos de Bachillerato y contado por aquella persona que había sido uno de sus principales artífices. Creí que sería algo motivador para los alumnos.

Así pues, me dispuse a asistir al mitin provisto de una grabadora de casetes portátil y de un ejemplar de la revista Historia 16, concretamente el número 13 de Historia de España, titulado De la dictadura a la democracia. Desarrollismo, crisis y transición (1959-1977), cuyos autores eran Juan Pablo Fusi, Sergio Vilar y Paul Preston, con la intención — si me concedía la entrevistade pedirle que me firmara una dedicatoria de esa publicación.

El auditorio estaba completo. Momentos antes de finalizar el mitin, abandoné el teatro y me dirigí a la puerta reservada exclusivamente para la entrada y salida de actores y personal de seguridad, en este caso. Alli, una vez identificado, le comenté a alguien de su seguridad mis intenciones de obtener una entrevista con Adolfo Suárez. Me respondieron que esperara porque lo tenían que consultar. Pasados unos instantes, me comunicaron que aguardase a que saliera el presidente y que me atenderia. Hasta ahora - pensé- he ido teniendo suerte.

Debía ser la mía la única cara que no conocía, porque al salir, en el vestíbulo, se dirigió directamente hacia mí con su habitual sonrisa, al tiempo que me extendió su mano para saludar y preguntarme qué deseaba. Le expliqué quién era yo, cuál era mi profesión y el propósito de mi entrevista, haciendo hincapié en que los destinatarios de sus palabras serían mis alumnos de $\mathrm{Ba}-$ chillerato. De entrada, no hubo una negativa. No debió parecerle mal la idea, pensé, aunque puso dificultades basadas en la falta de tiempo porque tenía a continuación una cena donde lo esperaban. Continué insistiendo, con el mayor respeto, en que la entrevista le ocuparía muy poco tiempo y sería una oportunidad única para mis alumnos. De pronto, como si dudara, volvió su cara hacia atrás para preguntarle a sus acompañantes locales cómo se 1lamaba el sitio en el que iban a ir a cenar. El Club Náutico, en Bajamar, le respondieron. ¿Conoce usted ese sitio?, me preguntó Adolfo Suárez. Le respondí afirmativamente y me indicó: Pues hacia alli nos dirigimos nosotros ahora. Si usted está allí cuando llegue, tendremos la entrevista antes de la cena.

No tengo que decir la sensación que experimenté. Es fácil de imaginar. Me quedé muy contento sabiendo que ahora todo dependía de mí. Así que, una vez me despedi de él mostrándole mi agradecimiento, bajé velozmente los distintos tramos de escaleras que separan la calle Virgen de La Luz de la calle 
O`Daly y, a veces corriendo y a veces caminando muy deprisa, llegué al Real Nuevo Club en su sede náutica, pues debía estar allí antes de la llegada del presidente, y me dispuse a esperarlo en el vestíbulo, en un sitio visible.

Momentos después, en coche, llegó Adolfo Suárez con sus acompañantes. Entró el primero en el Náutico y, al verme, me hizo una señal indicativa de que me dedicaba el tiempo a partir de ese momento. Tras unas primeras palabras, nos alejamos para sentarnos en la terraza, alejados del resto de su séquito. Le repetí, de nuevo, el sentido y finalidad de la entrevista, y comenzó a hablar

Adolfo Suárez (A. S.): Puedo explicar la Transición desde un punto de vista filosófico. Cuál fue la filosofia política que generó la Transición, pero explicar la Transición con todo lo que eso comporta... eso son prácticamente unas memorias...

Facundo Daranas (F. D.): Ya... pero a grandes rasgos, ¿cuáles fueron los principales problemas que usted tuvo...? De cara a unos alumnos de Bachillerato...

A. S.: Vamos a ver... Sí, será una contestación muy breve. Explicar muy...

F. D.: Aparece como medio tema... Tratado muy brevemente, porque todavía no hay documentación...

A. S: Entre otras cosas, porque todavia faltan mis memorias.

F. D.: Exactamente.

A. S.: Que tardarán mucho tiempo en publicarse.

F. D.: Esperemos, porque las memorias son sintoma de...

A. S: No, no, sobre todo es porque en este momento son desestabilizadoras. Pueden ser desestabilizadoras. Muchas de las cosas que se han escrito sobre la Transición no son correctas. Y yo tengo las pruebas evidentes... de cómo fue...

La filosofía que presidió toda la Transición política yo quizás la centraría en dos o tres mensajes que en un momento determinado mandé a los españoles. Uno, siendo ministro en el primer Gobierno tras la muerte de Franco, presidido por Carlos Arias, diciendo que había que elevar a la categoría política de normal lo que a nivel de calle era simplemente normal. Y otro, bueno... yo no creo en el determinismo histórico y, obviamente, cuando a mí se me indicaba que no existía ningún precedente histórico a partir del cual se pudiera pasar de un sistema autoritario a un sistema democrático, si no era por la vía revolucionaria... Yo decía que... bueno... eso era un dato a tener presente, pero que no era una afirmación dogmática. Que se podía crear el precedente. Y que, ciertamente, yo confiaba en que el precedente se pudiera crear porque era, quizás, la única puerta que se abría a los españoles... de consolidar un futuro sin previas revoluciones y sin previas descalificaciones de generaciones enteras.

Me interesó, por tanto, hacer un planteamiento politico, que ya lo tenía elaborado desde dos años antes de la muerte de Franco... 
F. D.: Perdón... usted tenía elaborado ese anteproyecto... ¿en base a qué, o debido a qué?

[En este momento me indicó que no grabara. Me comentó que, efectivamente él venía trabajando en esta posibilidad desde hacía algún tiempo. Todo ello, en el más absoluto sigilo, con algunas complicidades de otros compañeros. Y que, incluso, entre ellos se referian al por entonces principe Juan Carlos con el nombre en clave de El Rubio].

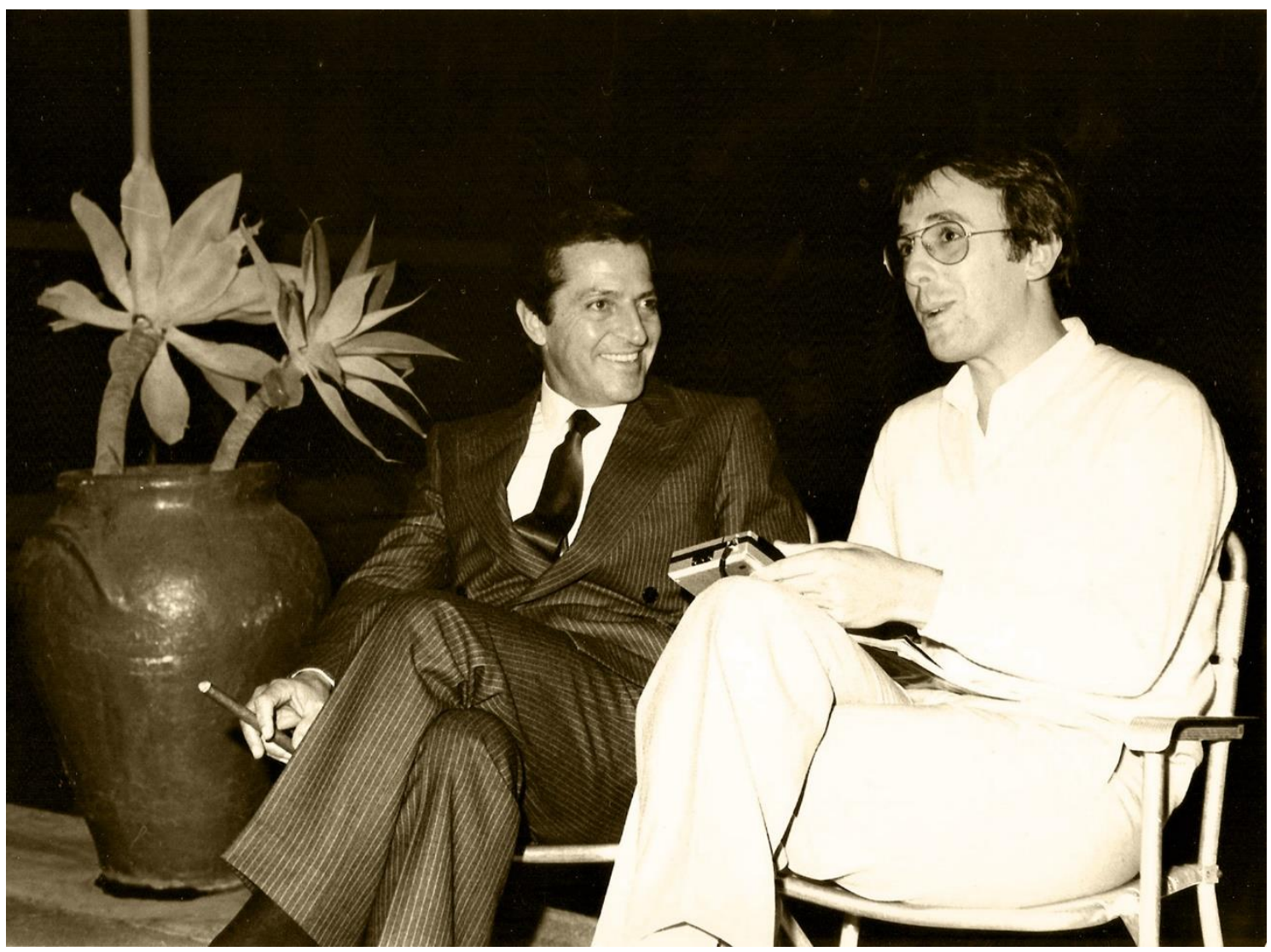

Imagen: El expresidente Suárez y el autor de la entrevista

A. S.: Yo era muy convencido que podiamos romper, digamos, las inci-dencias histórica. Que debíamos ofrecer a los españoles la oportunidad de que fueran capaces de sentar un precedente histórico de tal magnitud que permitiera, desde una legalidad vigente en aquel entonces, pasar a otra legalidad que comportara una ruptura con el sistema anterior, pero que, obviamente, pasaba por un periodo de transición.

Esa filosofia comportaba, en definitiva, la legalización de los partidos políticos, la devolución de la soberanía al pueblo español y la aceptación por parte de los demás de que yo era un gestor legítimo de los intereses de los españoles, aunque no fuera, evidentemente, representativo.

Afirmé al día siguiente de ser designado presidente del Gobierno que convocaría elecciones en junio de 1977 (promesa que cumplió); afirmé que devolvería - repito- la soberanía al pueblo español; y afirmé que en el futuro los gobiernos de la nación estarian formados con arreglo con la voluntad popular. 
Esa es la filosofia política que presidió toda la Transición: la que nos llevó a las elecciones de 1977 y la que permitió que a partir de entonces iniciáramos ese proceso de elaboración de una Constitución que fuera válida para todos los españoles y que, en definitiva, iba asentando poco a poco la democracia en España.

Todo eso, dicho así, con brevedad, ha comportado esfuerzos muy notables, obviamente, porque la tramitación de la Ley de Reforma Política tuvo que pasar por los órganos que en aquel entonces existían a nivel institucional en España, como eran el Consejo Nacional del Movimiento y las Cortes. Aquellos obstáculos se fueron superando, yo creo que desde la perspectiva de una enorme responsabilidad de todos los que participaron y colaboraron en el proyecto. Fue sometido a referéndum de la nación [...], que fue aprobado mayoritariamente por el pueblo español y que fue arrinconando las tesis de la ruptura y de la gestación de la reforma como camino más viable,

Procedimos a la legalización de los partidos politicos $y$, bueno... lo que le estoy diciendo me dirá usted que, ciertamente, esto ya lo sabe todo el mundo. Si lo que pretende es que ahora yo le dijera era, digamos, qué momentos y qué períodos fueron los

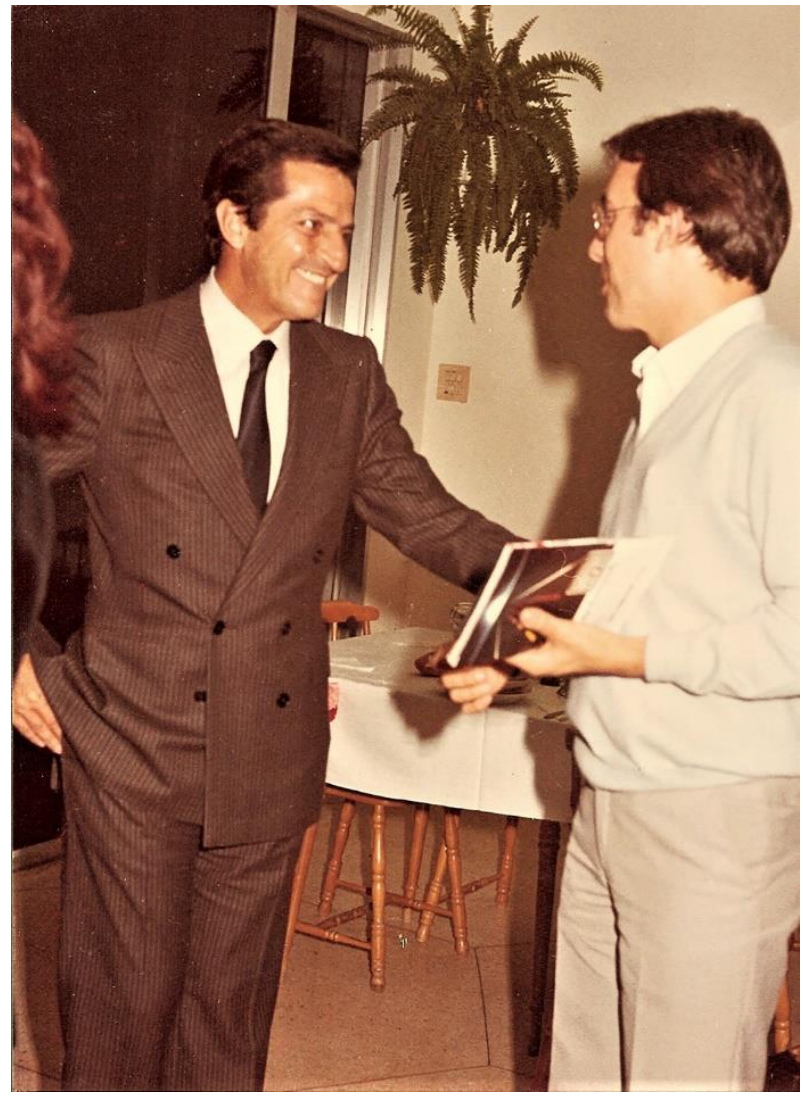

Imagen: El expresidente Suárez y el autor de la entrevista más dificiles y qué obstáculos hubo que salvar... eso pertenece todavía a la reserva que debo mantener, digamos, como expresidente de la nación.

F. D.: La legalización del Partido Comunista supuso algún escollo muy grave que salvar en aquel momento. En aquel Sábado Santo.

A. S.: Sí. Evidentemente. Estaba previsto legalizar el Partido Comunista. Me parecia absolutamente necesaria su legalización para que tuvieran credibilidad las elecciones del 77 y, además, por una razón también muy importante. Porque si yo afirmaba que era necesario obtener una fotografia lo más real posible de las diferentes ideologías existentes en España, no se podia tener un partido político de esas características en la clandestinidad. Comportó, desde luego, un riesgo importante. 
[En este momento quedó interrumpida la entrevista al acercarse uno de los acompañantes para indicarle que lo esperaban para la cena. Una pena, pensé, pero estaba muy satisfecho de ella. Fue este el momento en que le acerqué el ejemplar de la revista de Historia 16 para que me lo dedicara con su firma. Agradecido, me despedí, pero aún me aguardaba otra sorpresa. Su invitación para que lo acompañara a cenar, a lo que, después de alguna negativa, accedí gustoso].

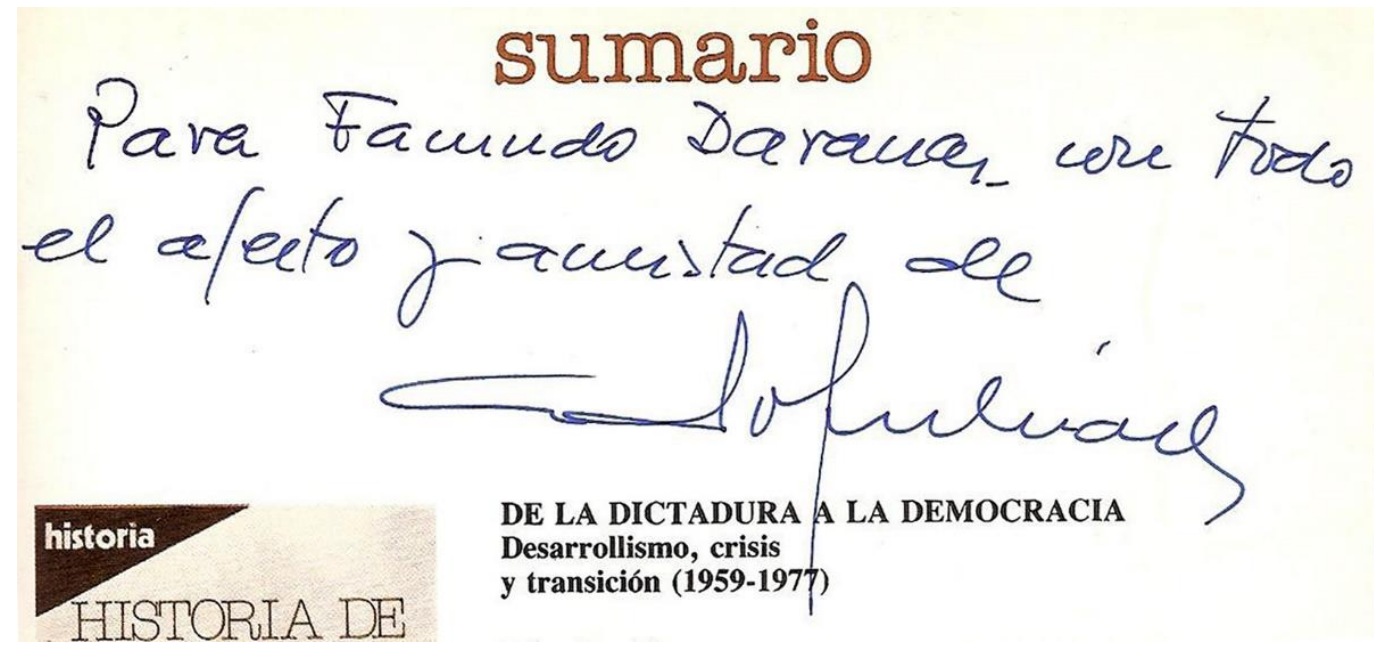

Años más tarde, el programa oficial de Historia de España de Bachillerato incluía el tema de la Transición española, y como motivación e introducción él mis alumnos siempre pudieron escuchar las palabras de Adolfo Suárez en variados formatos, que van desde la casete al Power-Point.

Para mí fue una experiencia muy bonita, de la que me siento orgulloso, y que aún hoy permanece grabada en mi memoria conservando hasta el más mínimo de los detalles. 